\title{
Editorial
}

\section{Decision Making Methods and Applications in Civil Engineering}

\author{
Jurgita Antucheviciene, ${ }^{1}$ Zdeněk Kala, ${ }^{2}$ Mohamed Marzouk, ${ }^{3}$ and Egidijus Rytas Vaidogas ${ }^{4}$ \\ ${ }^{1}$ Department of Construction Technology and Management, Faculty of Civil Engineering, Vilnius Gediminas Technical University, \\ Sauletekio Alèja 11, LT-10223 Vilnius, Lithuania \\ ${ }^{2}$ Department of Structural Mechanics, Faculty of Civil Engineering, Brno University of Technology, Veveř́ Street 95, \\ 60200 Brno, Czech Republic \\ ${ }^{3}$ Department of Structural Engineering, Faculty of Engineering, Cairo University, Giza 12613, Egypt \\ ${ }^{4}$ Department of Labour Safety and Fire Protection, Faculty of Civil Engineering, Vilnius Gediminas Technical University, \\ Sauletekio Aleja 11, LT-10223 Vilnius, Lithuania
}

Correspondence should be addressed to Jurgita Antucheviciene; jurgita.antucheviciene@vgtu.lt

Received 28 September 2015; Accepted 30 September 2015

Copyright (C) 2015 Jurgita Antucheviciene et al. This is an open access article distributed under the Creative Commons Attribution License, which permits unrestricted use, distribution, and reproduction in any medium, provided the original work is properly cited.

This special issue aims at providing recent developments about the decision making (DM) in the field of civil engineering. This field is vast and plays an important role in the life of modern society. A very large number of decisions must be made in the life cycle of constructed objects. The decisions will be required in the time span starting from conceptualisation of these objects and covering design, construction, occupation, and decommissioning. Methods of DM can facilitate making these decisions in formal and not fully formal, partially intuitive way. The present special issue provides numerous examples on how can this be done.

Articles published in this special issue prove that useful information for making construction related decisions can be obtained by methods which do not belong to a formal DM, for instance, sensitivity analysis, stochastic analysis, mathematical optimization, occupational safety, and risk assessment. Classical disciplines of engineering are also useful tool for facilitating decisions in civil engineering. However, all of these methods can be seen as means of providing input information for a formal DM.

The formal DM methods, with application of which this special issue is concerned to a large measure, were intensively developed and applied to various engineering systems in recent decades. They are known as methods of multiple criteria decision making (MCDM). Articles included in this issue show how to apply such MCDM methods as AHP, ANP, and
TOPSIS to making decisions related to construction industry and partially to transportation. Obviously, methods of MCDM were developed outside the field of civil engineering and their applications are very diverse. Several useful reviews of these methods are provided in the books $[1,2]$ as well as journal articles [3-8]. However, one can also find MCDM reviews devoted specifically to civil engineering as well as the related areas of infrastructure and asset management [911]. Systematically classified information on MCDM methods and applications can be found in the newly published review [12].

The problematics of DM cannot be resolved by means of MCDM alone. Sometimes intuition and sound engineering judgement will be as useful for making decisions as formal mathematical methods. A necessary base for such judgement is results of common engineering and sometimes managerial analysis. Several articles of this special issue demonstrate how to solve problems of DM in this not fully formal way.

In "Three-Dimensional Numerical Analysis of the Tunnel for Polyaxial State of Stress" by W. Qiu et al., the authors explore the mechanical behavior of rock masses around excavation under different value of intermediate principal stress. A new polyaxial strength criterion is used in numerical simulation to investigate the influence of intermediate principal stress. A mathematical relationship is established between 
polyaxial failure criterion and Mohr-Coulomb failure criterion and they are applied in the numerical simulation, respectively. Results indicate that there are some differences of intermediate principal stress influence on the mechanical behavior of rock masses based on the both criteria.

In "Solving Civil Engineering Problems by Means of Fuzzy and Stochastic MCDM Methods: Current State and Future Research" by J. Antucheviciene et al., a review of DM methods, developed for dealing with uncertainties by means of fuzzy logic and probabilistic modelling and applied to solving problems of civil engineering, is provided. Several methodological difficulties emerging from uncertainty quantification in MCDM are identified. Prospects of using MCDM under uncertainty in developing areas of civil engineering are discussed.

The paper "A Novel Model of Set Pair Analysis Coupled with Extenics for Evaluation of Surrounding Rock Stability" by $M$. Wang et al. studies the problem of evaluation of surrounding rock stability as a complex and uncertain problem, involving numerous factors of fuzziness, uncertainty, and variability. A novel DM model, based on the set pair analysis (SPA) coupled with extenics, considering incompatibility, certainty, and uncertainty of evaluation indicators, is presented to analyze the surrounding rock stability.

Q. Hou and X. Zhou present the paper "Cross-Efficiency Evaluation Method with Compete-Cooperate Matrix" and investigate the question of cross-efficiency evaluation method as an effective data envelopment analysis (DEA) method with self-assessment and peer-assessment to evaluate and rank decision making units (DMUs). In this paper, a symmetric (nonsymmetric) compete-cooperate matrix is introduced and compete-cooperate cross-efficiency method is proposed to evaluate DMUs with diverse (relative) relationships. Numerical demonstration is provided to illustrate the reasonability and practicability of the proposed method.

In "Naïve Bayesian Classifier for Selecting Good/Bad Projects during the Early Stage of International Construction Bidding Decisions" by W. Jang et al., a method for increasing firms' profit rates and enhancing the efficiency of Korean contractors bidding decisions during early stages of a project cycle is suggested. Naïve Bayesian classifier is used as a screening tool that increases practical applicability using binomial variables with limited information obtained during early stages of construction projects.

In the paper "Service Station Evaluation Problem in Catering Service of High-Speed Railway: A Fuzzy QFD Approach Based on Evidence Theory," X. Wu et al. offer the MCDM approach for the service station evaluation problem in catering service of high-speed railway (SSEP-CSHR). The selection of potential service stations for CSHR is carried out using two-phase fuzzy quality function deployment (FQFD) with regard to a series of practical criteria and basic requirements in context of CSHR.

J. Cho et al. propose quality function deployment (QFD) to select market products for building envelope solution in "QFD Based Benchmarking Logic Using TOPSIS and Suitability Index." Technique for Order of Preference by Similarity to Ideal Solution (TOPSIS) and Suitability Index (SI) are used to provide performance improvement criteria and allow analysis on suitability of the building envelope solution based on user's required performance criteria, respectively.

In "Planning Tunnel Construction Using Markov Chain Monte Carlo (MCMC)," J. P. Vargas et al. propose a simulation algorithm which can be regarded as a variant of the MCMC method. It provides the user with a reliable assessment of excavation times in case of utilizing the standard method of drilling and blasting.

In "Performance Requirements on Remodeling Apartment Housing and TOPSIS Evaluation" by J. Cho and J. Chun, the authors look into the problem of performance evaluation of remodeling apartment housing. They suggest applying the TOPSIS to measure performance improvement degree on remodeling design solutions before and after remodeling. The method presents the objective composite performance score with multiperformance properties and allows user to decide the weight for performance.

The paper "Use of a Combination of MRSS-ANP for Making an Innovative Landfill Siting Decision Model" by M. K. Younes et al. explores the use of a median ranked sample set (MRSS) and an analytic network process (ANP) when ranking the associated environmental, social, land use, and operational criteria and selecting a suitable landfill site. The proposed integrated model minimizes the uncertainty and the subjectivity of human judgments and may become a valuable tool for the decision makers.

Q. Wang et al. showed and applied a mechanical model of prestressed steel cantilever to study the optimal position of the transverse external tendon in the paper entitled "Structural Optimization of Steel Cantilever Used in Concrete Box Girder Bridge Widening," The reasonability and feasibility of the optimal design are verified by stress state analysis using finite element method. The structural optimization helps the designer to find the most suitable shape and layout of a steel cantilever from structural and architectural points of view.

The authors of "BIM Application to Select Appropriate Design Alternative with Consideration of LCA and LCCA" Y. Shin and K. Cho consider how to analyze the information needed to conduct life cycle assessment (LCA) and life cycle cost analysis (LCCA) using a building information modeling. Decision makers can use the results of the assessments at early phases of projects to evaluate different alternatives taking into account economic and environmental perspectives.

In "A Straight-Line Method for Analyzing Residual Drawdowns at an Observation Well" a new straight-line method to estimate the aquifer parameters by using the residual drawdowns at the observation is presented by M. Çimen. In hydraulic engineering, determination of the transmissivity and storage coefficients of a confined aquifer is important for effective groundwater resources.

The paper "Predicted Thermal Sensation Index for the Hot Environment in the Spinning Workshop" by R.-L. Yang et al. proposes a new heat index, named predicted thermal sensation (PTS) index, to effectively evaluate the general thermal sensation of the textile worker exposed to the hot environment in the spinning workshop. Compared to other indices, the PTS index can more effectively predict the mean thermal response of a large group of workers. 
The paper "Sustainability-Related Decision Making in Industrial Buildings: An AHP Analysis" by J. Cuadrado et al. proposes an application of AHP method to serve as a sustainability related DM tool in industrial building projects during the design stage. Accompanied by an economic valuation of the actions to be undertaken, this tool means that the most cost-effective solution may be selected from among the various options.

I.-H. Han et al. consider the problem of DM related to occupational safety on the construction site. In the paper "Decision Making Method Based on Importance-Dangerousness Analysis for the Potential Risk Behavior of Construction Laborers," they propose an analytical technique allowing to quantitatively assess the risk to construction workers. This technique can serve as a practical tool for making decisions concerning the potentiality of workplace accidents.

In "Map Matching Based on Conditional Random Fields and Route Preference Mining for Uncertain Trajectories" by M. Xu et al., the problem of offline map matching accuracy of uncertain GPS trajectories is investigated. A map matching algorithm based on conditional random fields (CRF) and route preference mining is proposed. The experimental results show that the proposed algorithm is more accurate than existing methods, especially in the case of a low sampling rate.

The present special issue does not crystallize any special problem or methodological stream of DM in civil engineering. It rather demonstrates how diverse problems of DM in the field of construction and related fields can be. Articles included in this issue are, to a great extent, a result of a random choice. Out of 63 manuscripts submitted to the special issue, only 17 were finally accepted for publication. Unfortunately, 8 manuscripts were simply withdrawn and we, guest editors, are very sad about this. Several of them were of very high scientific quality.

Despite the certain randomness inherent in the final selection of manuscripts for publication, we think that the special issue could be interesting to all those who have to make decisions in the vast field of civil engineering.

\section{Acknowledgments}

A large number of people contributed in various ways to making this special issue possible. First of all, we thank professor Edmundas Kazimieras Zavadskas for having proposed the topic of this issue. Let us also thank the authors of articles published in the issue for their contribution. We are grateful to all the reviewers for their valuable work.

$$
\begin{array}{r}
\text { Jurgita Antucheviciene } \\
\text { Zdeněk Kala } \\
\text { Mohamed Marzouk } \\
\text { Egidijus Rytas Vaidogas }
\end{array}
$$

[2] M. Ehrgott, J. R. Figueira, and S. Greco, Eds., Trends in Multiple Criteria Decision Analysis, Springer, New York, NY, USA, 2010.

[3] M. M. Wiecek, Matthias Ehrgott, G. Fadel, and J. Rui Figueira, "Multiple criteria decision making for engineering," Omega, vol. 36, no. 3, pp. 337-339, 2008.

[4] E. K. Zavadskas and Z. Turskis, "Multiple criteria decision making (MCDM) methods in economics: an overview," Technological and Economic Development of Economy, vol. 17, no. 2, pp. 397-427, 2011.

[5] M. Behzadian, S. K. Otaghsara, M. Yazdani, and J. Ignatius, "A state-of the-art survey of TOPSIS applications," Expert Systems with Applications, vol. 39, no. 17, pp. 13051-13069, 2012.

[6] E. K. Zavadskas, Z. Turskis, and S. Kildiene, "State of art surveys of overviews on MCDM/MADM methods," Technological and Economic Development of Economy, vol. 20, no. 1, pp. 165-179, 2014.

[7] A. Mardani, A. Jusoh, and E. K. Zavadskas, "Fuzzy multiple criteria decision-making techniques and applicationstwo decades review from 1994 to 2014," Expert Systems with Applications, vol. 42, no. 8, pp. 4126-4148, 2015.

[8] C. Kahraman, S. C. Onar, and B. Oztaysi, "Fuzzy multicriteria decision-making: a literature review," International Journal of Computational Intelligence Systems, vol. 8, no. 4, pp. 637-666, 2015.

[9] D. Jato-Espino, E. Castillo-Lopez, J. Rodriguez-Hernandez, and J. C. Canteras-Jordana, "A review of application of multicriteria decision making methods in construction," Automation in Construction, vol. 45, pp. 151-162, 2014.

[10] G. Kabir, R. Sadiq, and S. Tesfamariam, "A review of multicriteria decision-making methods for infrastructure management," Structure and Infrastructure Engineering: Maintenance, Management, Life-Cycle Design and Performance, vol. 10, no. 9, pp. 1176-1210, 2014.

[11] L. F. Gay and S. K. Sinha, "Resilience of civil infrastructure systems: literature review for improved asset management," International Journal of Critical Infrastructures, vol. 9, no. 4, pp. 330-350, 2013.

[12] A. Mardani, A. Jusoh, K. MD Nor, Z. Khalifah, N. Zakwan, and A. Valipour, "Multiple criteria decision-making techniques and their applications-a review of the literature from 2000 to 2014," Economic Research-Ekonomska Istraživanja, vol. 28, no. 1, pp. 516-571, 2015.

\section{References}

[1] J. R. Figueira, S. Greco, and M. Ehrgott, Eds., Multiple Criteria Decision Analysis: State of the Art Surveys, Springer, Berlin, Germany, 2005. 


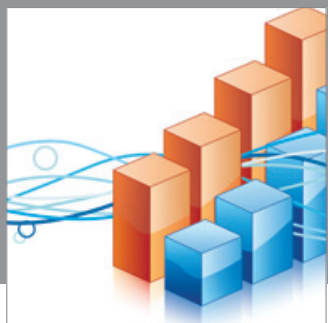

Advances in

Operations Research

mansans

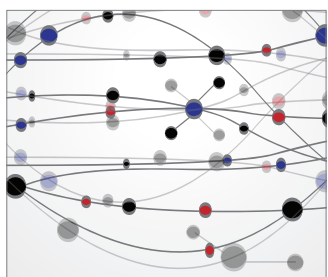

The Scientific World Journal
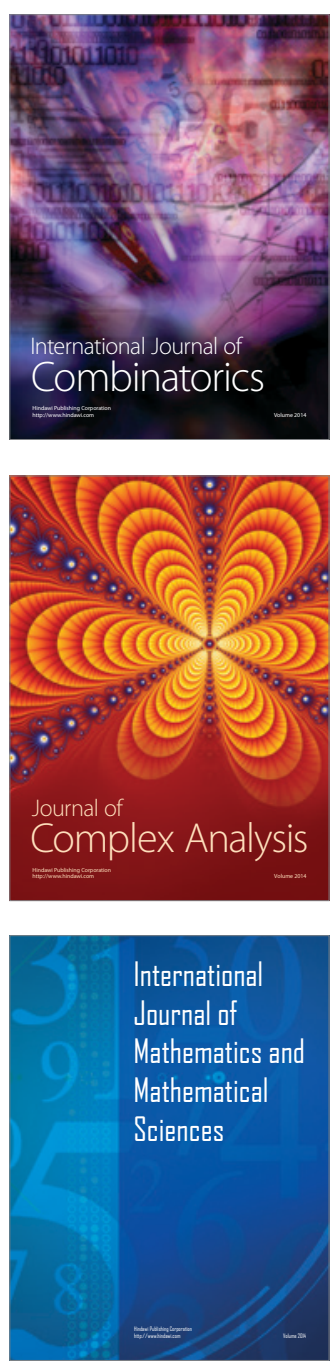
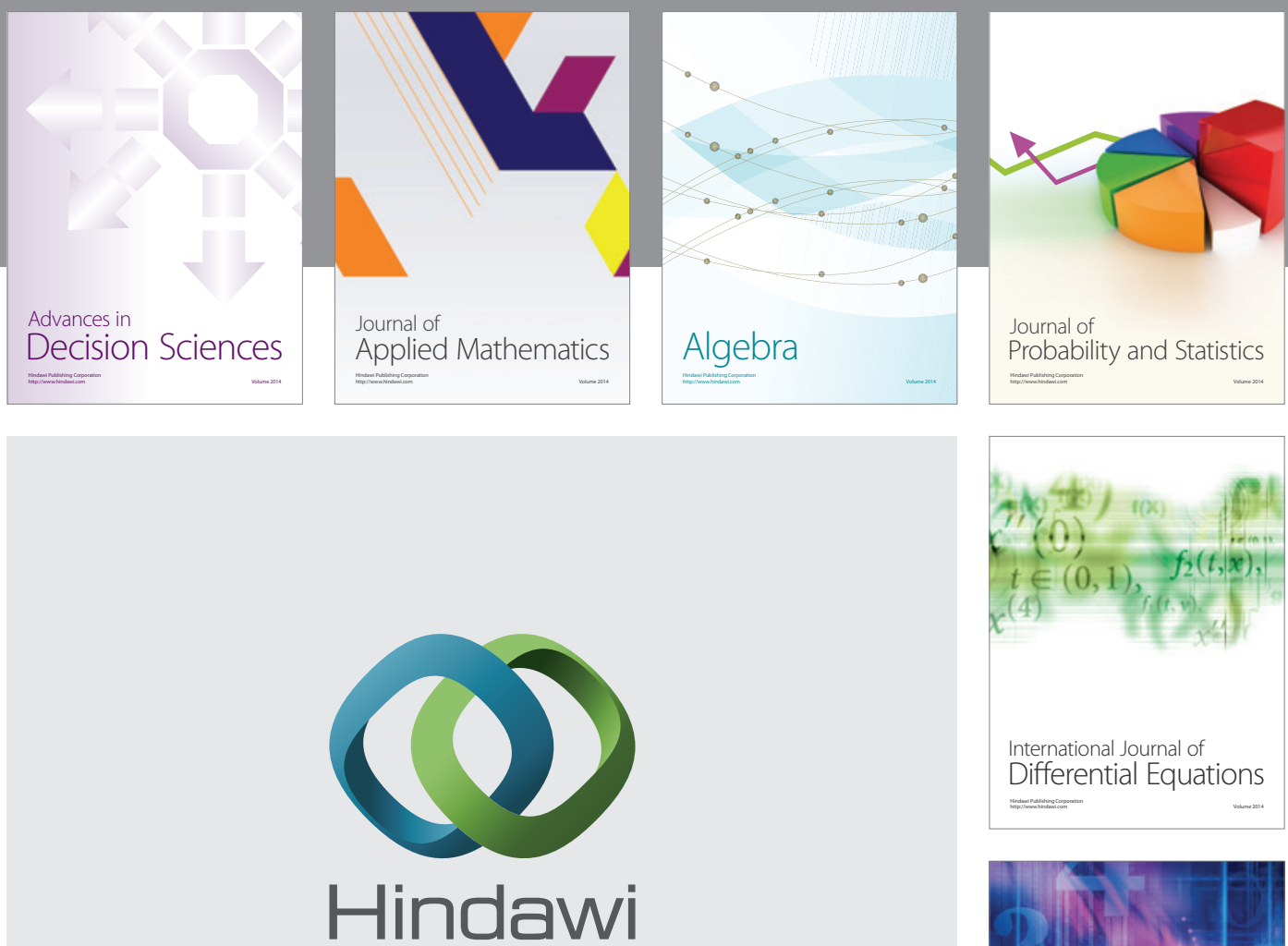

Submit your manuscripts at http://www.hindawi.com
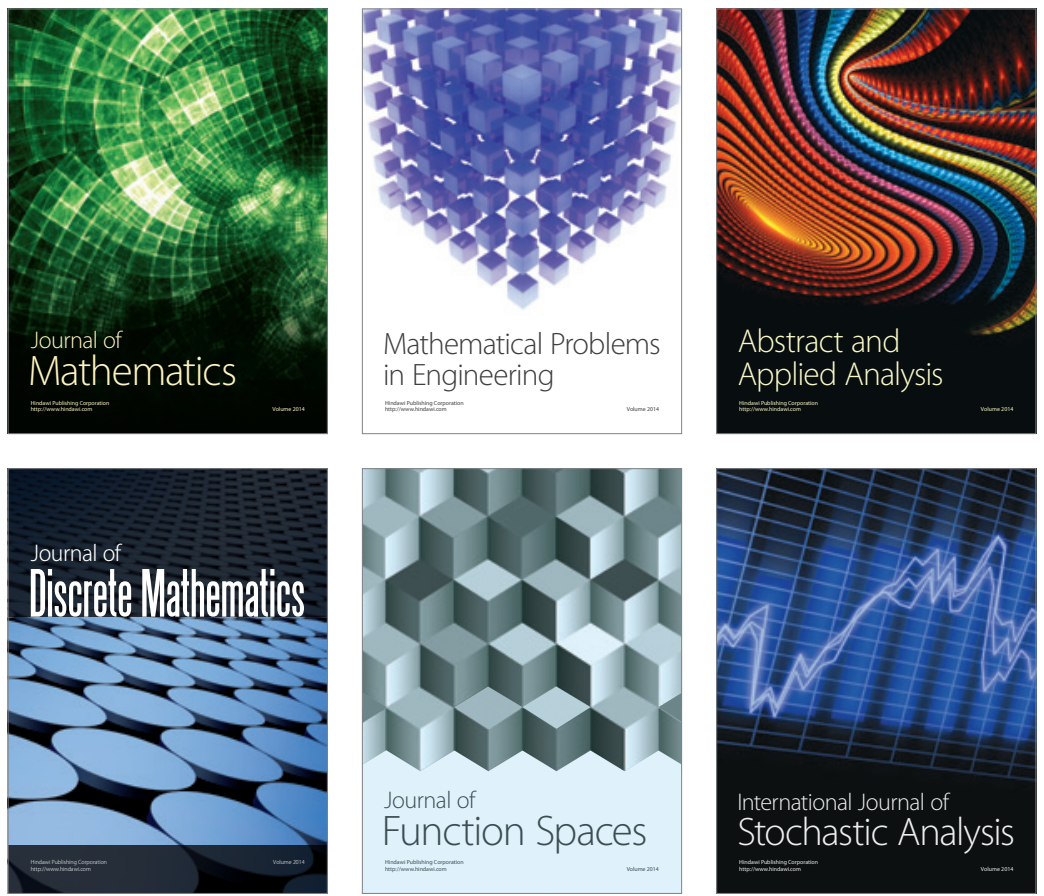

Journal of

Function Spaces

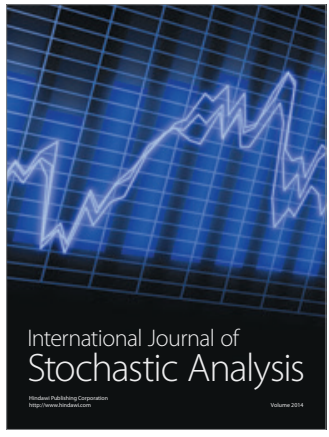

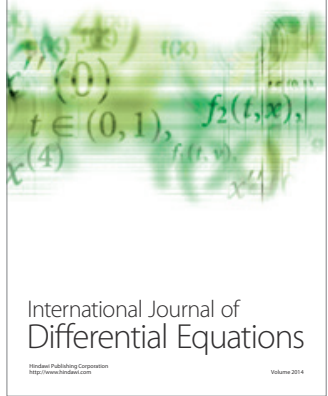
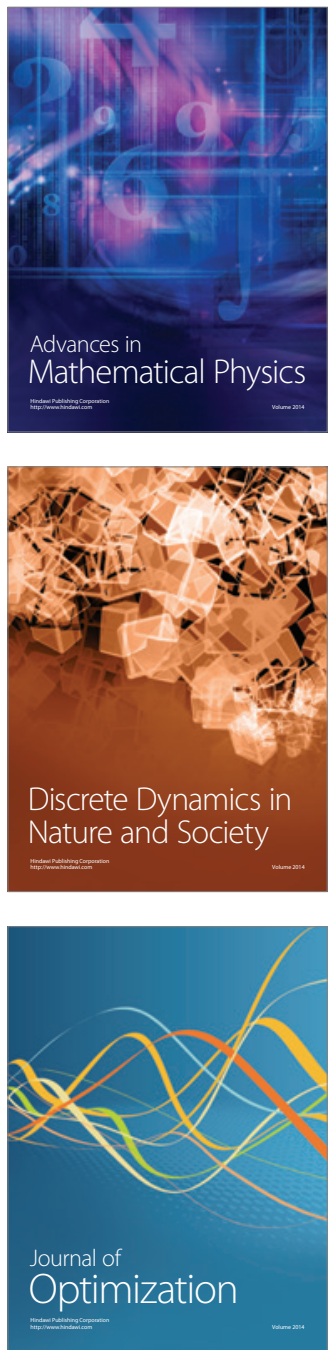